\title{
Chrysanthemum biotechnology: discoveries from the recent literature
}

\author{
Jaime A. Teixeira da Silva ${ }^{1 *}$, Dariusz Kulus ${ }^{2 *}$ \\ ${ }^{1}$ P. O. Box 7, Miki-cho post office \\ Ikenobe 3011-2, Kagawa-ken 761-0799, Japan \\ ${ }^{2}$ Department of Ornamental Plants and Vegetable Crops - Laboratory of Biotechnology \\ University of Technology and Life Sciences in Bydgoszcz \\ Bernardyńska 6, 85-029 Bydgoszcz, Poland
}

\begin{abstract}
The in vitro propagation of chrysanthemum (Chrysanthemum $\times$ grandiflorum (Ramat.) Kitam.), one of the world's most important ornamentals, is a very well-studied topic and shows numerous strides each year. This mini-review condenses the knowledge that has been published on chrysanthemum biotechnology, especially in vitro culture in the wider plant science literature. In 2013 and 2014, important strides were made in molecular breeding, particularly anti-viral strategies, including through transgenics, and our understanding of flower genetics and flowering regulation.
\end{abstract}

Key words: cryopreservation, explant, in vitro flowering, molecular markers, organogenesis, plant growth regulators, regeneration, rhizogenesis, synthetic seeds, transgenic

\section{INTRODUCTION}

Ornamental chrysanthemum (Chrysanthemum $\times$ grandiflorum (Ramat.) Kitam., previously Dendranthema grandiflorum (Ramat.) Kitamura and Chrysanthemum morifolium Ramat.; Shinoyama et al. 2006) is one of the most important ornamental species on the market. Although the nomenclature and taxonomy of chrysanthemum is a topic of fiery debate (D.J. Nicholas Hind, personal communication), Chrysanthemum $\times$ grandiflorum (Ramat.) Kitam. will be used consistently throughout this review. The number of chrysanthemum cultivars is incredibly large with more than 15,000 listed in Japan alone while The National Chrysanthemum Society of Britain lists over 6000 cultivars (Datta 2013). Traditional reproduction and breeding methods are no longer able to meet the growing requirements of the market. Today, in order to satisfy the demands of consumers, novel biotechnological tools need to be applied. Biotechnology incorporates fields of study such as in vitro culture and micropropagation, cryopreservation, molecular technologies, genetic transformation, synthetic seed technology, secondary metabolite production and acclimatization. To date, several dozen studies have been published related to the biotechnology of ornamental chrysanthemum. Tissue culture is a basic - but important - science for several of the applied biotechnologies. To date, several comprehensive reviews on chrysanthemum biotechnology exist (Rout and Das 1997, Teixeira da Silva 2003a, 2004a, Shinoyama et al. 2006, Kulus et al. 2013, Teixeira da Silva et al. 2013). However, many new papers are published each year. One 
specialized in vitro tissue culture and propagation technique is the regeneration from flowers, which can be a source of novel characters due to the chimeric (or mutant) nature of regeneration from disc or ray florets (Datta and Teixeira da Silva 2006). By better understanding the biotechnology of this ornamental, plants could be generated - either through traditional breeding, mutation breeding or through transgenic technologies - with increased resistance to biotic (pests and diseases) and abiotic (temperature, salinity, hydric, etc.) stresses, with cut flowers with longer postharvest life and thus storage ability, and novel flower colours, leaf shape or architecture (Datta 2012, Teixeira da Silva et al. 2013).

Given the rapidly evolving nature of research related to this ornamental, this mini-review covers studies that have emerged on chrysanthemum biotechnology primarily over the past two years. Advances were made in two major areas: tissue culture, and molecular genetics, including marker technology, transgenics, and flowering genetics.

\section{RECENT ADVANCES IN CHRYSANTHEMUM RESEARCH}

\section{Advances in tissue culture}

Tissue culture is an important technique that serves as the basis for other more complex research, such as molecular studies. Work with disinfected plant material, however, is only possible under aseptic conditions. Deein et al. (2013a, b) and Thepsithar et al. (2013), in a bid to sterilize in vitro medium without autoclaving, applied a wide range of essential oils (EOs) from medicinal plants, as well as chemical disinfectants, in the culture of the nodes or shoots of 'Moneymaker Improved'. Betel, clove, cinnamon, lavender, holy basil, lemon, tea tree, and turmeric EO (each at different concentrations: $0.9 \mathrm{~mL} \mathrm{dm}^{-3}$ $-12.6 \mathrm{~mL} \mathrm{dm}^{-3}$ ) could all result in $100 \%$ sterilization of medium, equivalent to autoclaving. Similarly, the following sterilants could also provide $100 \%$ medium sterilization: $2 \%$ iodine $+2.4 \%$ potassium iodide, $2 \%$ merbromine solution, $10 \%$ povidoneiodine, $6 \%$ sodium hypochlorite or $0.1 \%$ thimerosal at $1.8 \mathrm{~mL} \mathrm{dm}^{-3}$. These compounds, however, also affected the growth of shoots by reducing their height and fresh weight, but stimulating the elongation of roots instead. This method provides a low-cost alternative in laboratories where no autoclave is available, although the cost of such EOs being cheaper than autoclaving is questionable. The disinfection of explants is another matter. Ethanol, sodium or calcium hypochlorite or mercuric chloride solutions are the most frequently used disinfection agents. However, these chemical compounds often damage plant tissue (which is highly unwanted with chimeras, especially 'Variegata' types) or are ineffective in the elimination of endophytic bacterial and fungal contaminations. Silver and copper nanocolloids also present antibacterial, antifungal and antiviral activities but are less toxic (they do not require rinsing with sterile water) and may penetrate the cell by plasmodesmas in order to kill endophytes (Dimkpa et al. 2012). Experiments conducted by Tymoszuk (2014) confirmed the usefulness of $\mathrm{Ag}$ and $\mathrm{Cu}$ nanocolloids to eliminate bacterial and fungal contaminations in chrysanthemum in vitro cultures. The nanocolloids demonstrated satisfactory antibacterial and antifungal activity, even at a low concentration and short disinfection period. Additionally, no plant tissue damage was observed. Therefore, these nanocolloids can be considered as a simple and efficient alternative to other disinfection methods.

The ability to establish an effective regeneration system for chrysanthemum allows for important germplasm to be sustained through clonal propagation. Zhou et al. (2014) used a simple culture to intensively proliferate shoot tips on $0.5 \mathrm{mg} \mathrm{dm}^{-3} \mathrm{BA}+0.1 \mathrm{mg} \mathrm{dm}^{-3} \mathrm{NAA}$-supplemented Murashige and Skoog (MS; Murashige and Skoog 1962) medium to reduce the incidence of seven viruses and viroids (Chrysanthemum stunt viroid (CSVd), Chrysanthemum chlorotic mottle viroid (CChMVd), Chrysanthemum virus B, Cucumber mosaic virus, Tobacco mosaic virus, Tomato spotted wilt virus, and Tomato aspermy virus), which are a common problem in vegetatively propagated chrysanthemum.

In an experiment using 11 cultivars conducted by Lim et al. (2012) with different explant types (stems, leaves and petioles), stems exhibited the highest frequency of shoot organogenesis and mean number of shoots/explant, in a genotypeindependent manner. Expanding on earlier studies, and using a single cultivar, 'Shuhou-no-Chikara', Teixeira da Silva (2014a), tested several novel aspects of in vitro culture, making four new discoveries: 1) Alternatives to agar (as the gelling agent) for chrysanthemum tissue culture. Gellan gum and agar produced more shoots and roots than all other gelling agents tested (Bacto agar, phytagel, oatmeal agar, potato dextrose agar, barley starch and corn starch). In the study conducted 
by Lim et al. (2012) and Naing et al. (2014a), also Gelrite resulted in higher shoot number per explant than agar, agarose and Phytagel while silver nitrate inhibited shoot induction. 2) Several alternative liquid-based medium additives (low and full fat milk, Coca-Cola ${ }^{\circledR}$, coffee, Japanese green, Oolong and Darjeeling teas) stunted plant growth and decreased the chlorophyll content (SPAD value) of leaves. 3) Plants grown on medium with refined sucrose or table sugar was similar, but poor when stevia (Stevia rebaudiana (Bertoni) Bertoni) extract, which is also an alternative sweetener in food products, was used. 4) Photoautotrophic micropropagation significantly increased the shoot mass, even when plant density was doubled while aeration of the culture vessel improved plantlet growth. Using the same cultivar, Teixeira da Silva (2014b) examined the response to a wide range of plant growth regulators (PGRs), under light and dark conditions. There were three new key findings: 1) Explants responded similarly in the light and dark, for both disc and ray florets. 2) Twelve out of 30 PGRs, when tested alone, provided a weak organogenic response while the remaining 18 PGRs resulted in no or $<5 \%$ explant response. 3) Organogenesis was reported for the first time in chrysanthemum flower tissue for five PGRs: adenine sulphate (Ads), $N^{6}-[\Delta 2$-isopentenyl $]$ adenine (2iP), picloram, coconut water $(\mathrm{CW})$, and phloroglucinol (PG). Ads, 6-benzyladenine (BA) and kinetin (Kin) resulted in shoot formation, 2iP, picloram, 2,4-dichlorophenoxyacetic acid (2,4D) and thidiazuron (TDZ) formed callus, CW formed shoots and callus, while PG, indole-3acetic acid (IAA), indole-3-butyric acid (IBA) and $\alpha$-naphthaleneacetic acid (NAA) formed roots, but each was effective at different concentrations, with the effective range differing for each PGR.

Naing et al. (2014a) claimed that 12.3 shoots/ explant could form from leaf segments of 'Vivid Scarlet' in the presence of $1 \mathrm{mg} \mathrm{dm}^{-3} \mathrm{BA}$ and $2 \mathrm{mg}$ $\mathrm{dm}^{-3}$ NAA. Also Tymoszuk and Zalewska (2014a) showed that the regeneration of adventitious shoots from 'Cool Time' ligulate florets occurred when the medium contained the adequate concentration of both BA and NAA. Most shoots per flower explant (8.89-36.09) regenerated on medium supplemented with $2.0 \mathrm{mg} \mathrm{dm}^{-3} \mathrm{BA}+0.3 \mathrm{mg} \mathrm{dm}^{-3} \mathrm{NAA}$ and on media with $2.0-3.0 \mathrm{mg} \mathrm{dm}^{-3} \mathrm{BA}+0.5 \mathrm{mg} \mathrm{dm}^{-3}$ NAA. Most shoots regenerated on transversely- or lengthwise-cut into half or on the entire pierced ligulate florets - horizontally inoculated, with the abaxial side on the medium (Tymoszuk and
Zalewska 2014b). These findings can be very useful in breeding by separation of chimera components (especially sectorial and mericlinal types) and saving new genotypes/cultivars, many of which up-to-date were lost, due to the lack of efficient regeneration systems. However, in chrysanthemums a substantial part of the shoots regenerated from floral explants do not reach the length allowing them to be easily cut off from the explant, making the division while multiplication and transferring onto the rooting medium difficult. This problem was overcome by Jerzy et al. (2013) by adding kinetin into the medium. The length of the shoots regenerated from ligulate florets on the medium with $1 \mathrm{mg} \mathrm{dm}^{-3} \mathrm{Kin}$ added was almost three-fold higher than the length of the shoots formed from the explants present throughout the culture period on the medium with BA and IAA. The subculture of regenerating ligulate florets after 7 weeks from the solid to liquid medium increased the number of regenerating shoots and stimulated their elongation (Tymoszuk and Zalewska 2012).

Zawadzka et al. (2013), aiming to show the possibility and benefit of bacterization of tissue cultures, cultured multiple 'Ludo' chrysanthemum shoots placed in sterilized perlite with liquid medium in the presence of bacteria (Paenibacillus glucanolyticus, Curtobacterium pusillum and Methylobacterium extorquens), themselves isolated from hosta (Hosta Tratt.) or raspberry (Rubus occidentalis L.) tissue cultures. After 9 weeks, C. pusillum stimulated axillary shoot formation, $M$. extorquens stunted shoot growth and $P$. glucanolyticus increased the number and length of shoots and root length.

Since somatic embryogenesis (regeneration of embryos from vegetative tissues) is still commonly believed to be the most efficient micropropagation technique, usefull also in genetic transformation, new research associated with it occure every year. The Naing et al. (2013a, 2013b) papers bring new information about the in vitro response of two rarely studied chrysanthemum cultivars. Naing et al. (2013a) claimed to establish primary and secondary somatic embryogenesis from in vitro leaf explants of 'Euro' and from 'Baeksun' "petal" explants (Naing et al. 2013b). In 'Euro', MS medium supplemented with $2 \mathrm{mg} \mathrm{dm}^{-3} 2,4-\mathrm{D}$ and $2 \mathrm{mg} \mathrm{dm}^{-3}$ Kin was optimal (42 \pm 5.97 embryos/explant after 5 weeks of culture) while for 'Baeksun', $1 \mathrm{mg} \mathrm{dm}^{-3}$ 2,4-D and $3 \mathrm{mg} \mathrm{dm}^{-3}$ BA sufficed (56.3 embryos/ explant after 5 weeks of culture). Tymoszuk et al. (2014) determined the optimal parameters of the 
'Cool Time' flower explant for embryo regeneration. The best results (5.7 embryos/explant; 85\% explants regenerating) were obtained when transverselycut-into-half ligulate florets were inoculated onto MS medium with $1 \mathrm{mg} \mathrm{dm}{ }^{-3} \mathrm{Kin}$ and $4 \mathrm{mg}$ $\mathrm{dm}^{-3} 2,4-\mathrm{D}$. All of this research will facilitate the genetic transformation and micropropagation of Chrysanthemum cultivars. One should keep in mind though, that isolation and conversion of somatic embryos of some chrysanthemum cultivars is very difficult, even if the embryogenic potential is high.

\section{Advances in breeding}

Due to a high level of heterozygosity and selfincompatibility, chrysanthemum rarely forms seeds, which makes traditional breeding very difficult. For example, Natalia Miler (personal communication), after conducting dozens of pollinations, obtained just a few seeds. Moreover, even if produced, seeds contain a small amount of nutrients and are not viable. Biotechnology tools allow valuable genotypes to be saved by transferring zygotic embryos to in vitro cultures. Embryo rescue was used to obtain intergeneric hybrids

Table 1. Effects of various cryopreservation procedures on the survival of chrysanthemum shoot tips

\begin{tabular}{|c|c|c|c|}
\hline Cultivar & Cryopreservation procedure & Survival $[\%]$ & Reference \\
\hline Lady Salmon & $\begin{array}{l}\text { - } \mathrm{MS}^{*}+0.09 \mathrm{M} \text { sucrose (7 days) } \\
\text { - } \mathrm{MS}+0.09 \mathrm{M} \text { sucrose }+0 / 10 / 20 / 30 \mu \mathrm{M} \text { ABA (7 days) } \\
\text { - } \text { Encapsulation in } 3 \% \text { sodium-alginate } \\
\text { - } \text { 4-days osmotic dehydration } \\
\text { - } 3 \text {-h air desiccation } \\
\text { - Immersion in } \mathrm{LN} \\
\text { - Recovery on } \mathrm{MS}+0.1 \mathrm{mg} \mathrm{dm}{ }^{-3} \mathrm{BA}\end{array}$ & $\begin{array}{l}35 / 65 / 40 / 20 \\
\text { (survival for } 0 / 10 / 20 / 30 \mu \mathrm{M} \\
\text { ABA, respectively) }\end{array}$ & \multirow{2}{*}{$\begin{array}{l}\text { Zalewska and } \\
\text { Kulus (2014) }\end{array}$} \\
\hline Lady Rosy & 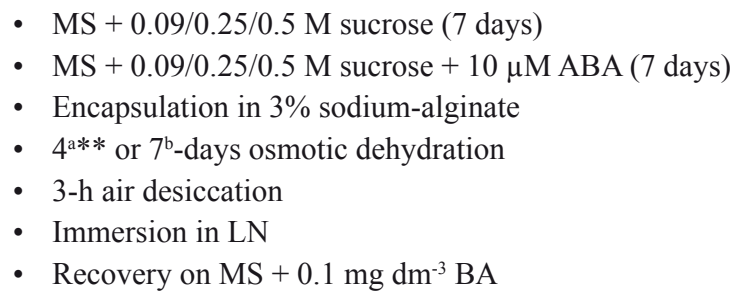 & $\begin{array}{l}56^{\mathrm{a}}-67^{\mathrm{b}} / 44^{\mathrm{a}}-38^{\mathrm{b}} / 44^{\mathrm{a}}-25^{\mathrm{b}} \\
\text { (survival for } 0.09 / 0.25 / 0.5 \mathrm{M} \\
\text { sucrose, respectively) }\end{array}$ & \\
\hline Lady Rosy & $\begin{array}{l}\text { - } \mathrm{MS}+0.09 \mathrm{M} \text { sucrose ( } 7 \text { days }) \\
\text { - } \mathrm{MS}+0.09 \mathrm{M} \text { sucrose }+10 \mu \mathrm{M} \text { ABA ( } 7 \text { days }) \\
\text { - } \text { Encapsulation in } 3 \% \text { sodium-alginate } \\
\text { - } 4 \text {-days osmotic dehydration } \\
\text { - } 1 / 2 / 3 / 4 / 5 \text {-h air desiccation } \\
\text { - } \text { Immersion in } \mathrm{LN} \\
\text { Recovery on } \mathrm{MS}+0.1 \mathrm{mg} \mathrm{dm}^{-3} \mathrm{BA}\end{array}$ & $\begin{array}{l}0 / 0 / 8 / 63 / 43 / 25 \\
\text { (survival for } 1 / 2 / 3 / 4 / 5 \text {-h air } \\
\text { desiccation, respectively) }\end{array}$ & \multirow{2}{*}{$\begin{array}{l}\text { Zalewska and } \\
\text { Kulus (2014) }\end{array}$} \\
\hline Lady Salmon & $\begin{array}{l}\text { - } \mathrm{MS}+0.09 \mathrm{M} \text { sucrose (7 days) } \\
\text { - } \mathrm{MS}+0.09 \mathrm{M} \text { sucrose }+10 \mu \mathrm{M} \mathrm{ABA} \text { (7 days) } \\
\text { - } \text { Encapsulation in } 3 \% \text { sodium-alginate } \\
\text { - } 4 \text {-days osmotic dehydration } \\
\text { - } 3 \text {-h air desiccation } \\
\text { - Immersion in LN } \\
\text { - Recovery on } \mathrm{MS}+0.1 \mathrm{mg} \mathrm{dm}^{-3} \mathrm{NAA} / \mathrm{BA} / \mathrm{Kin}\end{array}$ & $\begin{array}{l}20 / 40 / 45 \\
\text { (survival for NAA/BA/Kin, } \\
\text { respectively) }\end{array}$ & \\
\hline $\begin{array}{l}\text { Lady Orange }^{\mathrm{c}} \\
\text { Lady Salmon }^{\mathrm{d}}\end{array}$ & $\begin{array}{l}\text { - } \mathrm{MS}+0.09 \mathrm{M} \text { sucrose (7 days) } \\
\text { - } \mathrm{MS}+0.09 \mathrm{M} \text { sucrose }+10 \mu \mathrm{M} \mathrm{ABA} \text { (7 days) } \\
\text { - } \text { Encapsulation in } 3 \% \text { sodium-alginate } \\
\text { - } \text { 4-days osmotic dehydration } \\
\text { - } 3 \text {-h air desiccation } \\
\text { - Immersion in LN } \\
\text { - Recovery on } \mathrm{MS}+0.25 / 0.50 / 0.75 / 1.0 \mathrm{mg} \mathrm{dm}^{-3} \mathrm{Kin}\end{array}$ & $\begin{array}{l}47^{\mathrm{c}}-13^{\mathrm{d}} / 31^{\mathrm{c}}-18^{\mathrm{d} /} / 28^{\mathrm{c}}-42^{\mathrm{d}} / 31^{\mathrm{c}}-60^{\mathrm{d}} \\
\text { (survival for } \\
0.25 / 0.50 / 0.75 / 1.0 \mathrm{mg} \mathrm{dm}^{-3} \\
\text { Kin, respectively) }\end{array}$ & $\begin{array}{l}\text { Zalewska and } \\
\text { Kulus (2013) }\end{array}$ \\
\hline
\end{tabular}

*MS - Murashige and Skoog (1962) medium, ABA - abscisic acid, LN - liquid nitrogen, BA - 6-benzyladenine (syn. BAP, Teixeira da Silva 2012), NAA - 1-naphthaleneacetic acid, Kin - kinetin

**Lower-case letters $\left({ }^{\mathrm{a}},{ }^{\mathrm{b}},{ }^{\mathrm{c}},{ }^{\mathrm{d}}\right)$ refer to defined experimental factors 
between C. grandiflorum 'Nannongxiaoli' and Artemisia vulgaris L. 'Variegata' (Zhu et al. 2014). These hybrids (19 from a total of 124 regenerated plants), which displayed flowering characteristic of D. morifolium (syn. C. grandiflorum), showed greater resistance to aphid (Macrosiphoniella sanbourni) infestation and Alternaria leaf spot than the 'Nannongxiaoli' parent, but less than the 'Variegata' parent. Another example of applying floral explants and tissue cultures in breeding is haploid production. However, until 2013, this had never been achieved with chrysanthemum. In 2013, Miler and Muszczyk for the first time obtained a haploid via gynogenesis, but, the process efficiency was very low.

Somaclonal variation (alternation induced under in vitro conditions) is one of the fastest and cheapest ways of producing new cultivars. However, the main problem with the somaclonal variation is that the effectiveness of forming new variants is low. In order to find a more efficient source of somaclones, Miler and Zalewska (2014) regenerated shoots from two explant types, leaves and internodes, in eight chrysanthemum cultivars belonging to three groups: Albugo and its mutant, Alchimist and its two mutants, and Satinbleu and its two mutants, and discovered that: 1) Novel phenotypes of chrysanthemum arise as a result of the regeneration of adventitious shoots in vitro from leaves only. 2) The alternation of phenotypes is usually associated with the triggering of the synthesis of carotenoids in ligulate florets. These findings shed new light on aspects of chrysanthemum breeding.

\section{Advances in medium and long-term storage}

Research conducted by Kulus and Zalewska (2014a) confirmed the possibility of utilizing synthetic seed technology for the medium-term storage of four chrysanthemum cultivars of the Lady group. Nearly $90 \%$ of encapsulated explants grew on control MS medium 30 days after inoculation but encapsulation strongly limited the rooting of microshoots $(24 \%$ rhizogenesis efficiency). It was also shown that by inoculating synthetic seeds on medium with $0.1 \mathrm{mg}$ $\mathrm{dm}^{-3}$ Kin stimulated germination (73\% after 60 days of culture on MS0 medium and $90 \%$ on medium with Kin) and rooting after transferring to rooting medium with $2 \mathrm{mg} \mathrm{dm}^{-3}$ IAA (75\% rhizogenesis efficiency on MS0 and 90\% on Kin-supplemented medium).

In the past two years much work has been conducted on cryopreservation (long-term storage in liquid nitrogen, at $-196^{\circ} \mathrm{C}$ ) of the Lady group and other chrysanthemum cultivars (Tab. 1). Wang et al. (2014) developed a highly efficient dropletvitrification cryopreservation for 'Japanese Red' and 'Xizi Oiuzhuang'. The procedure resulted in $43-83 \%$ shoot regrowth rates. In addition, assessment of genetic stability showed no variation after applying simple sequence repeats and flow cytometry. Research conducted by Kulus et al. (2013) with 'Lady Yellow', on the other hand, showed that encapsulation-dehydration was most optimal, since it provided the highest survival of the frozen apical buds (approx. 60\%; Fig. 1A). The lowest survival was observed after applying vitrification, which ensured the survival of only $10 \%$ of the shoot tips (Fig. 1B). In addition, these studies have also confirmed the positive role of abscisic acid (ABA) in securing the plant material. Research conducted by Zalewska and Kulus (2013, 2014) showed that the optimal concentration of ABA in the preculture MS medium for 'Lady Salmon' was $10 \mu \mathrm{M}$. Both higher $(20$ and $30 \mu \mathrm{M})$ and lower $(0 \mu \mathrm{M})$ concentrations did not improve the results.
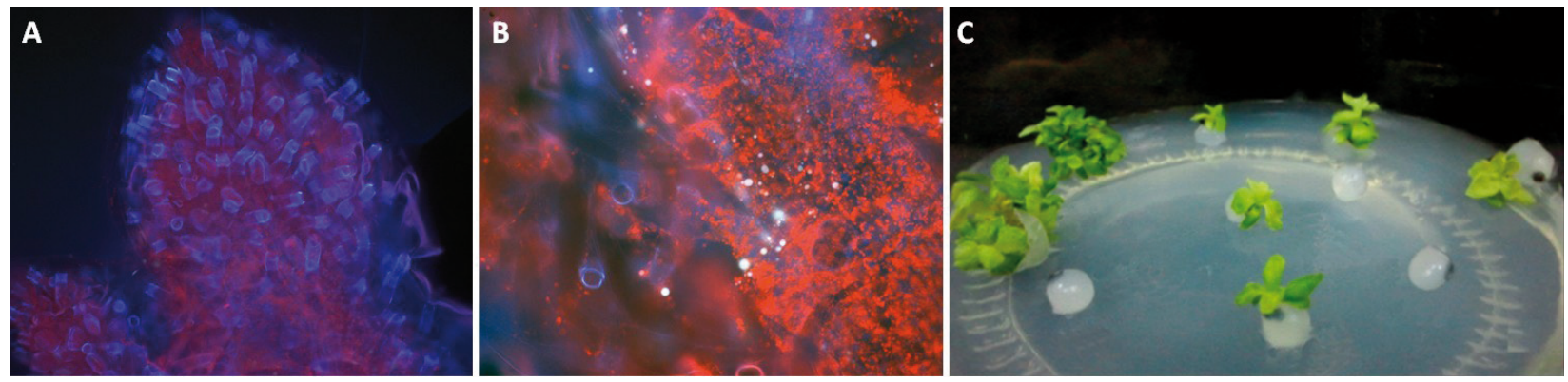

Figure 1. Image of chrysanthemum shoot tips after cryopreservation (A, B - 'Lady Yellow', photos from fluorescent microscope, C - 'Lady Rosy'): A - Fully intact shoot tip with no visible injuries (blue colour - represents cell walls; Zalewska et al. 2012), B - Highly injured tissue with visible signs of protoplasm leakage (red colour represents chlorophyll autofluorescence) and lipid bodies (white dots; unpublished photo, Dariusz Kulus), C - Post-thawing regeneration of single and multiple shoots from cryopreserved by encapsulation-dehydration technique 1-2 mm shoot tips on MS medium with $0.1 \mathrm{mg} \mathrm{dm}^{-3} \mathrm{BA}$ (unpublished photo, Dariusz Kulus) 
Higher sucrose concentrations $(0.25$ and $0.5 \mathrm{M})$ during preculture limited both the survival and growth capacity (observed even without freezing) of 'Lady Salmon' explants and the effectiveness of rhizogenesis, stimulating the growth of multiple shoots instead. However, sucrose concentrations lower than $0.09 \mathrm{M}$ also had a negative impact on the cryopreservation efficiency (survival and regeneration rates) of both 'Lady Salmon' and 'Lady Orange', and the use of a sugar gradient during preculture $(0.09 / 0.18 \mathrm{M}$, seven days each) did not improve the results. However, replacing sucrose with another carbohydrate such as $0.25 \mathrm{M}$ glucose or $0.25 \mathrm{M}$ trehalose could improve these results. Surprisingly, lower temperatures during preculture $\left(5^{\circ} \mathrm{C}\right)$ did not influence 'Lady Rosy' cryopreservation efficiency in comparison to the $22^{\circ} \mathrm{C}$ control (similar 55\% survival). Zalewska and Kulus (2014) also excluded the possibility of using a one-step osmotic dehydration (18-45 h incubation in a concentrated $0.5-0.9 \mathrm{M}$ solution of sucrose), proving at the same time that the explants had a high tolerance to osmotic stress (severaldays' incubation in solutions with high sucrose concentrations up to $1.0 \mathrm{M}$ ). That research showed, however, that some chrysanthemum cultivars (e.g. 'Lady Rosy') are very sensitive to desiccation (air drying). A typically used 5-h physical dehydration under a laminar air-flow cabinet resulted in a 70\% decrease in the survival of both control and frozen 'Lady Rosy' explants. The optimal drying time was 3-4 h. Such vulnerability of the plant material to desiccation is a serious problem, since the removal of water (and prevention from ice crystallization) is a necessary step in achieving an efficient cryopreservation protocol (Kulus and Zalewska 2014b). The composition of the recovery medium was the most essential step when developing a cryopreservation protocol (Zalewska and Kulus 2013, 2014). On control PGR-free MS medium, only $15 \%$ of explants grew 30 days after thawing. Similar results were observed after applying 0.1 $\mathrm{mg} \mathrm{dm}{ }^{-3}$ of NAA alone. The addition of cytokinins $\left(0.1 \mathrm{mg} \mathrm{dm}^{-3} \mathrm{BA}\right.$ or Kin) was key in stimulating further growth of the thawed explants (40-50\%). However, even though BA stimulated the fastest and most intensive regeneration of microshoots, it often resulted in the formation of highly deformed multiple shoots with short internodes and callus regeneration (Fig. 1C). A typical morphology was observed after applying 0.1-1.0 $\mathrm{mg} \mathrm{dm}^{-3} \mathrm{Kin}$. The concentration used did not affect the growth potential of the thawed explants, but it influenced the morphology and the rooting efficiency of the microshoots. Higher concentrations of Kin $(>0.25$

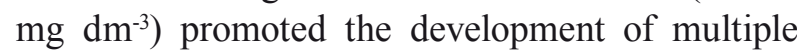
shoots and inhibited stem elongation, stimulating their thickening instead (Zalewska and Kulus 2013). Also higher Kin concentrations inhibited rooting (50\% of shoots regenerated roots when applying $0.25 \mathrm{mg} \mathrm{dm}^{-3} \mathrm{Kin}$ and $30 \%$ with $0.5 \mathrm{mg} \mathrm{dm}^{-3} \mathrm{Kin}$ ). In order to avoid problems with photosynthesis, it is also beneficial to maintain the thawed explants in the dark or reduced light conditions (Kulus and Zalewska 2014b). These described results, as well as a thorough scrutiny of the wider low-temperature and cryopreservation literature for chrysanthemum indicate clearly that cryopreservation can be considered as a future method of long-term storage of valuable chrysanthemum genetic resources (Teixeira da Silva et al. 2014).

\section{Advances in transgenics, molecular breeding, genetics and molecular markers}

Molecular and genetic studies of chrysanthemum advanced the most in the past two years. Yin et al. (2013) isolated a full-length cDNA of the alcohol dehydrogenase gene $(\mathrm{CgADH})$ from chrysanthemum (Chrysanthemum zawadskii Herbich), advancing our knowledge about the response of this landscaping ornamental to hydric stress caused by hypoxia during waterlogging. $\mathrm{CgADH}$ induction and expression were suppressed in the presence of ethylene, which the authors claim was countered by the formation of aerenchyma and adventitious roots. This suppression could however, be reversed by adding 1-MCP, an inhibitor of ethylene action.

Plant genetic transformation requires appropriate choice of antibiotics for regeneration of transformed tissues and elimination of Agrobacterium, and minimal concentration of selective agents for the selection of putative transformants during transformation. According to Naing et al. (2014b) Carbenicillin and Clavamox had less inhibitory effects on number of shoots per explant than cefotaxime, but superior plant growth (i.e. number of leaves, number of roots, plant height, and fresh weight) was observed in shoots treated with 125 $\mathrm{mg} \mathrm{dm}{ }^{-3}$ Clavamox. These findings suggest that Clavamox can effectively replace carbenicillin or cefotaxime in Agrobacterium-mediated genetic transformation studies of chrysanthemum, improving the regeneration effectiveness.

One of the important applications of transgenics is to alter plant growth and architecture. Lee 
et al. (2013) generated transgenic plants using Agrobacterium tumefaciens $\mathrm{C} 58 \mathrm{C} 1$ that showed significantly lower lateral branching than nontransgenic plants $(43 \%$ vs $5 \%$ nodes without axillary buds) following transformation with the LeLs (late embryonic, lateral suppressor) antisense gene, providing a practical way to manipulate plant architecture, which would have practically useful applications in greenhouse growth. In a similar earlier study, Huh et al. (2013) obtained five transgenic 'Jinba' plants - using A. tumefaciens $\mathrm{C} 58 \mathrm{C} 1$ - carrying antisense $L s$ cDNA. These plants showed decreased axillary branching, although this was strongly dependent on the season (highest percentage of viable axillary buds when planted in April, followed by planting in August, then June), confirming the role of $L s$ genes in axillary meristem initiation. Selected transformants also showed changes to floral structure, for example the change of the pistil into a stamen-like structure.

Other important use of genetic transformation may be associated with increased production of secondary metabolites since some recent studies proved that chrysanthemum extracts are valuable in cancer (skin, breast, colon and prostate) and AIDS treatment (Hosni et al. 2013, Kim et al. 2013).

Another important application of transgenics is in the development of pest and disease resistance. Sen et al. (2013) used Agrobacterium-mediated transformation to introduce the rice chitinase gene (the product of which is decomposing the exoskeleton of insects) into 'Snow Ball' internodes, obtaining four putative transformants on hygromycin-supplemented medium. Even though RT-PCR (reverse transcription polymerase chain reaction) and Southern blot analyses showed integration of the transgene, and even though the authors claimed a $2.2 \%$ transformation efficiency, none of the transformants were resistant to Septoria obesa, which causes leaf spot disease. Mitiouchkina et al. (2013) introduced single and double copies of the gene encoding for the virus B coat protein via Agrobacterium-mediated transformation into C. morifolium 'White Snowdon', as confirmed by PCR, RT-PCR and Western blotting, although no virus-resistant plants were reported, or tested. This indicates, that still much work needs to be done in the field of genetic transformation.

Molecular identification of pathogens is another novel achievement of plant biotechnology. CChMVd is a serious chrysanthemum viral disease. To detect this viroid more easily and efficiently, Park et al. (2013) used loop-mediated isothermal amplification
(LAMP) that, in comparison to PCR, amplifies DNA with high specificity, efficiency and rapidity under isothermal conditions (Notomi et al. 2000). Using several primers, the authors could detect two strains of CChMVd. This would allow for simple field testing of potentially infected plants. Savitri et al. (2013) found that storing 'Ency' shoot tips that had been infected by CSVd at $4{ }^{\circ} \mathrm{C}$ for two months could reduce infection by $43 \%$ while storage at this temperature for three months, together with constant treatment with $50-100 \mathrm{mg} \mathrm{dm}^{-3}$ ribavirin (an antiviral), could totally eliminate CSVd infection. Their study, however, only employed PCR for CSVd detection.

Genetic markers based on the modified PCR reaction are the most popular methods of identifying polymorphisms on the DNA level used in plant biotechnology. In the past random amplified polymorphic DNA (RAPD) primers were most commonly used, due to their simplicity and low-cost. Their disadvantage, however, is lack of reproducibility. AFLP (amplification fragments length polymorphism) is more reliable but also much more expensive and time-consuming. ISSR primers (inter-simple sequence repeats) link the advantages of both, and therefore, nowadays they are the most popular (Baliyan et al. 2014). Mukherjee et al. (2013) used 20 RAPD and four ISSR primers to fingerprint 40 commercial chrysanthemum cultivars. A phylogram was obtained following UPGMA analysis, polymorphic index and primer index were calculated and principal co-ordinate analysis was applied. Consequently, using these different techniques, cultivars could be clearly differentiated and the genetic distance between them could be established. Kang et al. (2013) used AFLP markers to distinguish in vitro explants derived from standard-type 'Migok' from gammairradiated mutants. Since the highest amount of polymorphism (72.1\%) was detected in plants that had been irradiated with $30 \mathrm{~Gy}$, the authors considered this to be the most effective dosage for inducing in vitro genetic variations in this cultivar.

\section{Advances in the understanding of flowering and flowering-related mechanisms}

Using a purple gamma-ray irradiated mutant 'ARTIpurple', and analyzing expressed sequence tags (ESTs), Sung et al. (2013) identified novel cDNAs encoding enzymes of specific plant metabolic pathways that reflect the unique expression caused by gamma-ray mutation - invariably one of the most popular breeding methods. They isolated 
796 unigenes from ray florets, some of which were involved in carbohydrate and lipid metabolic pathways, or were transcription factors or signal transduction genes. Relative to the wild-type 'Argus', a light pink cultivar, 'ARTI-purple' showed decreased CmMYBI $(\mathrm{Cm}=$ Chrysanthemum morifolium) expression which is important since CmMYB1 shared high similarity with AtMYB4 and AtMYBL2, which are negative regulators of anthocyanin and flavonol accumulation, respectively. Expression of enoyl-ACP reductase and S-malonyltransferase, two genes involved in lipid metabolism, was also lower in 'ARTI-purple' flowers.

Two important studies advanced our knowledge of flower genetics and flowering regulation in chrysanthemum. An antiflorigen (CsAFT; Chrysanthemum seticuspe Anti-florigenic FT/ TFL1 family protein) produced in the leaves of wild chrysanthemum (Chrysanthemum seticuspe) under a non-inductive photoperiod was shown to systemically inhibit flowering (Higuchi et al. 2013). This would prevent precocious flowering and enable the year-round supply of marketable flowers by manipulating day length. The following was learn about CsAFT: a) expression is primarily in the leaves; b) it acts systemically to inhibit flowering; c) it plays a predominant role in the obligate photoperiodic response; d) it inhibits flowering by reducing the flower-inductive activity of CsFTL3, a $C$. seticuspe orthologue of FLOWERING LOCUS T (FT), a florigen; e) dusk triggers CsAFT expression.

Huang et al. (2013), in a bid to induce red and blue flowers, which currently do not form part of the colour repertoire of C. morifolium, attempted to rebuild the delphinidin pathway by downregulating $\mathrm{CmF3}^{\prime} \mathrm{H}$ (flavanone 3-hydroxylase gene hydroxylated at the $3^{\prime}$ position) using RNAi and overexpressing the Senecio cruentus $F^{\prime} 5^{\prime} H$ (PCFH) (flavanone 3-hydroxylase gene hydroxylated at the $3^{\prime}$ and $5^{\prime}$ positions) gene in chrysanthemum. Brighter red flowers with a higher cyaniding content were obtained as a result of the $\mathrm{CmF3}^{\prime} \mathrm{H}$ gene but $\mathrm{F}^{\prime} 5^{\prime} \mathrm{H}$ only exhibited $\mathrm{F} 3{ }^{\prime} \mathrm{H}$ activity and could not result in blue flowers.

\section{Advances in greenhouse studies}

In order to reduce energy costs (which are after manpower the second major factor contributing to high production costs), typically used fluorescent lamps can be substituted with light-emitting diodes (LEDs). Using LEDs can also enhance plantlet quality. Ouzounis et al. (2014) tested several blue to red ratios of LEDs on the growth of greenhouse C. grandiflorum 'Coral Charm'. They found that plants were stunted under $40 \%$ blue $+60 \%$ red while $100 \%$ red resulted in lowest total biomass. While photosynthesis was not affected, stomatal conducted in all red + blue LED ratios were higher than $100 \%$ red and the control. Flavonoid content was lowest under $100 \%$ red while phenolic acids and flavonoids increased in treatments with a high blue light ratio. These findings may find wider use in controlling the plants morphology.

\section{CONCLUSIONS}

Chrysanthemum continues to command top economic rank in terms of ornamentals globally and may be one of the most important model ornamental crops alongside rose. Despite this, many objectives have yet to be achieved, including the genotype-independence of protocols. Topics that still deserve greater attention include the effective induction of flowers in vitro, the use of Agrobacterium rhizogenes to stimulate hairy root production for secondary metabolite production, transcriptomic analyses, and the use of newer molecular markers to advance our knowledge of the genetic background of cultivars and to shed light on the taxonomic problems of this plant. Given the existence of as-yet wide-ranging unreported errors in recent and past studies, the accuracy of the published chrysanthemum literature needs to be critically re-assessed through post-publication peer review with the objective of correcting the literature (Teixeira da Silva 2013, 2014c).

\section{ACKNOWLEDGEMENTS}

The authors thank Dr. Judit Dobránszki (University of Debrecen, Hungary) for providing difficult-toaccess literature and the anonymous reviewers for useful suggestions. The authors thank Dr. D.J. Nicholas Hind, Head of Compositae Research, Royal Botanic Gardens, Kew, UK, for fruitful discussion on the nomenclature and taxonomy of garden chrysanthemums.

\section{REFERENCES}

Baliyan D., Sirohi A., Kumar M., Kumar V., Malik S., Sharma S., et al., 2014. Comparative genetic diversity analysis in chrysanthemum: A pilot study based on morpho-genomic traits and ISSR markers. Sci. Hortic. 176: 164-168. 
DATTA S.K., 2012. Success story of induced mutagenesis for development of new ornamental varieties. In: M.I. Kozgar and S. Khan (eds), Induced Mutagenesis in Crop Plants. Biorem. Biodiv. Bioavail. 6 (Special Issue 1): 15-26.

DatTA S.K., 2013. Chrysanthemum morifolium Ramat. a unique genetic material for breeding. Sci. Culture 7-8: 307-313.

Datta S.K., Teixeira da Silva J.A., 2006. Role of induced mutagenesis for development of new flower colour and type in ornamentals. In: Floriculture, Ornamental and Plant Biotechnology: Advances and Topical Issues (1st Ed., Volume I). J.A. Teixeira da Silva (ed.), Global Science Books Ltd., Isleworth, UK: 640-645.

Deein W., Thepsithar C., Thongpukdee A., 2013a. In vitro culture medium sterilization by chemicals and essential oils without autoclaving and growth of chrysanthemum nodes. World Acad. Sci., Engin. Technol. 78: 1038-1041.

Deein W., Thepsithar C., Thongpukdee A., 2013 b. Growth of chrysanthemum explants on MS medium sterilized by disinfectants and essential oils. Int. J. Biosci., Biochem. Bioinformatics 3(6): 609-613.

Dimkpa C.O., McLean J.E., Britt D.W., Anderson A.J., 2012. Bioactivity and biomodification of $\mathrm{Ag}, \mathrm{ZnO}$, and $\mathrm{CuO}$ nanoparticles with relevance to plant performance in agriculture. Ind. Biotechnol. 8: 344-357.

Higuchi Y., Narumi T., Oda A., Nakano Y., Sumitomo K., FUKAI S., et al., 2013. The gated induction system of a systemic floral inhibitor, antiflorigen, determines obligate short-day flowering in chrysanthemums. Proc. Nat. Acad. Sci. USA 110(42): 17137-17142.

Hosni K., Hassen I., Sebel H., Casabianca H., 2013. Secondary metabolites from Chrysanthemum coronarium (garland) flowerheads: Chemical composition and biological activities. Ind. Crops Prod. 44: 263-271.

Huang H., Hu K., Han K-T., XIAng Q-Y., Dai S-L., 2013. Flower colour modification of chrysanthemum by suppression of $F 3^{\prime} H$ and overexpression of the exogenous Senecio cruentus F3'5'H gene. PLoS One 8(11): e74395.

Huh Y.J., Han B.H., Park S.K., Lee S.Y., Kil M.J., PAK C.H., 2013. Inhibition of chrysanthemum axillary buds via transformation with the antisense tomato lateral suppressor gene is season dependent. Hort. Environ. Biotechnol. 54(3): 280-287.

Jerzy M., Zalewska M., Tymoszuk A., 2013. Effect of kinetin on the elongation of adventitious shoots regenerated in vitro from ligulate florets in Chrysanthemum $\times$ grandiflorum /Ramat./ Kitam. $8^{\text {th }}$ International Symposium on In Vitro Culture and Horticultural Breeding, Coimbra, Portugal: 89.

Kang E.J., Lee Y.M., Sung S.Y., Ha B.K., Kim S.H., Kim D.S., et al., 2013. Analysis of the genetic relationship of gamma-irradiated in vitro mutants derived from standard-type chrysanthemum cv. Migok. Hort. Environ. Biotechnol. 54(1): 76-81.

Kiм C., KIm M-C., KIm S-M., Nam D., ChOI S-H., KIm S-H., et al., 2013. Chrysanthemum indicum L. extract induces apoptosis through suppression of constitutive STAT3 activation in human prostate cancer DU145 cells. Phytother. Res. 27(1): 30-38.

Kulus D., 2014. Zastosowanie kultur tkankowych w mikrorozmnażaniu chryzantem (Utilization of tissue culture in micropropagation of chrysanthemum). In: Nauka Niejedno ma Imię. J. Flizikowski (ed.), Wydawnictwo Uczelniane UTP, Bydgoszcz, Poland: 63-72.

Kulus D., Mikula A., Zalewska M., 2013. Cryopreservation: an efficient tool to combat genetic erosion phenomenon in agriculture and horticulture. IVth International Scientific Symposium for $\mathrm{PhD}$ Students and Students of Agricultural Colleges - Innovative researches for the future of agriculture and rural areas development, Bydgoszcz: 61.

Kulus D., ZALEwSKA M., 2014a. In vitro plant recovery from alginate encapsulated Chrysanthemum $\times$ grandiflorum /Ramat./ Kitam. shoot tips. Prop. Ornamental Plants 14(1): 3-12.

Kulus D., Zalewska M., 2014b. Cryopreservation as a tool used in long-term storage of ornamental species - a review. Sci. Hortic. 168: 88-107.

Lee S.Y., Kim J.H., Cheon K.S., LeE E.K., Kim W.H., Kwon O.H., et al., 2013. Phenotypic and molecular characteristics of second clone $\left(\mathrm{T}_{0} \mathrm{~V}_{2}\right)$ plants of the LeLs-antisense gene-transgenic chrysanthemum line exhibiting non-branching. J. Plant Biotechnol. 40: 192-197 (in Korean with English abstract).

Lim K-B., Kwon S.J., LeE S.I., Hwang J-Y., NAING A.H., 2012. Influence of genotype, explant source, and gelling agent on in vitro shoot regeneration of chrysanthemum. Hort. Environ. Biotechnol. 53(4): 329-335.

Miler N., Muszczyk P., 2013. Regeneration of callus and shoots from ovules and ovaries of chrysanthemum in vitro. $8^{\text {th }}$ International Symposium on In Vitro Culture and Horticultural Breeding, June 2-7 Coimbra, Portugal, Book of abstracts: 58.

Miler N., ZalewsKa M., 2014. Somaclonal variation of chrysanthemum propagated in vitro from different explants types. Acta Sci. Pol., Hortorum Cultus 13(2): 69-82.

Mitiouchkina T.Y., Firsov A.P., Dolgov S.V., 2013. Transgenic crysanthemum [sic] plants transformed with the gene encoding for the virus B coat protein. Russian Agric. Sci. 39(5-6): 431-434.

Mukherjee A.K., Dey A., Acharya L., Palai S.K., PAndA P.C., 2013. Studies on genetic diversity in elite varieties of Chrysanthemum using RAPD and ISSR markers. Indian J. Biotechnol. 12: 161-169.

Murashige T., Skoog F., 1962. A revised medium for rapid growth and bioassays with tobacco tissue culture. Physiol. Plant. 15: 173-179. 
NAing A.H., Kim C.K., Yun B.J., Jin J.Y., Lim K.B., 2013a. Primary and secondary somatic embryogenesis in Chrysanthemum cv. Euro. Plant Cell, Tiss. Organ Cult. 112: 361-368.

Naing A.H., Min J.S., Park K.I., Chung M.Y., Lim S.H., Lim K.B., etal., 2013b. Primary and secondary somatic embryogenesis in Chrysanthemum (Chrysanthemum morifolium) cv. 'Baeksun' and assessment of ploidy stability of somatic embryogenesis process by flow cytometry. Acta Physiol. Plant. 35: 2965-2974.

Naing A.H., Jeon S.M., Han J.S., Lim S.H., Lim K.B., KIM C.K., 2014a. Factors influencing in vitro shoot regeneration from leaf segments of Chrysanthemum. Comptes Rendus Biol. 37: 383-390.

NAing A.H., PARK K.I., Lim S.H., Kim C.K., 2014 b. Appropriate choice of antibiotics for plant regeneration and optimization of selective agents to be used in genetic transformation of chrysanthemum. Plant Omics J. 7(4): 237-243.

Notomi T., Okayama H., Masubuchi H., Yonekawa T., Watanabe K., Amino N., et al., 2000. Loop-mediated isothermal amplification of DNA. Nucleic Acid Res. 28(12): 1-7.

Ouzounis T., Fretté X., Rosenqvist E., Ottosen C-O., 2014. Spectral effects of supplementary lighting on the secondary metabolites in roses, chrysanthemums, and campanulas. J. Plant Physiol. 171: 1491-1499.

Park J.G., Jung Y.C., KIL E.J., Kim J.D., TraN D.T., Cног S.K., et al., 2013. Loop-mediated isothermal amplification for the rapid detection of Chrysanthemum chlorotic mottle viroid (CChMVd). J. Virological Methods 193(1): 232-237.

Rout G.R., DAS P., 1997. Recent trends in the biotechnology of Chrysanthemum: a critical review. Sci. Hortic. 69 (3-4): 239-257.

Savitri W.D., Park K.I., JeOn S.M., Chung M.Y., Han J.S., KIM C.K., 2013. Elimination of Chrysanthemum stunt viroid (CSVd) from meristem tip culture combined with prolonged cold treatment. Hort. Environ. Biotechnol. 54(2): 177-182.

Sen S., Kumar S., Ghani M., Thakur M., 2013. Agrobacterium mediated genetic transformation of chrysanthemum (Dendranthema grandiflora Tzvelev) with rice chitinase gene for improved resistance against Septoria obesa. Plant Pathol. J. 12: 1-10.

Shinoyama H., Anderson N., Furuta H., Mochizuki A., Nomura Y., Singh R.P., et al. 2006. Chrysanthemum biotechnology. In: Floriculture, Ornamental and Plant Biotechnology: Advances and Topical Issues (Volume I, 1st Edn). J.A. Teixeira da Silva (ed), Global Science Books, Ltd., Isleworth, UK: 140-163.

Sung S.Y., Kim S.H., Velusamy V., Lee Y.M., Ha B.K., KIM J.B., et al., 2013. Comparative gene expression analysis in a highly anthocyanin pigmented mutant of colorless chrysanthemum. Mol. Biol. Rep. 40: 5177-5189.
Teixeira DA Silva J.A., 2003. Chrysanthemum: advances in tissue culture, postharvest technology, genetics and transgenic biotechnology. Biotechnol. Adv. 21: 715-766.

TeIXeIRA DA Silva J.A., 2004. Ornamental chrysanthemums: improvement by biotechnology. Plant Cell, Tissue Organ Cult. 79: 1-18.

Teixeira da Silva J.A., 2012. Is BA (6-benzyladenine) BAP (6-benzylaminopurine)? Asian Australasian J. Plant Sci. Biotech. 6 (Special issue 1): 121-124.

Teixeira DA Silva J.A., 2013. The need for postpublication peer review in plant science publishing. Frontiers Plant Sci. 4 (Article 485): 3.

Teixeira da Silva J.A., 2014a. Novel factors affecting in vitro shoot culture of chrysanthemum (Dendranthema $\times$ grandiflora (Ramat.) Kitamura). Bot. Lithuanica 20(1): 27-40.

Teixeira DA Silva J.A., 2014b. Organogenesis from chrysanthemum (Dendranthema $\times$ grandiflora (Ramat.) Kitamura) petals (disc and ray florets) induced by plant growth regulators. Asia-Pacific J. Mol. Biol. Biotechnol. 22(1): 145-151.

TeiXeira DA Silva J.A., 2014c. Recent retraction cases in plant science that show why post-publication peer review is essential. J. Advancement Engin. Technol. 1(3): 4.

Teixeira da Silva J.A., Kim H.H., Engelmann F., 2014. Chrysanthemum low-temperature storage and cryopreservation: a review. Plant Cell, Tissue Organ Cult., DOI: 10.1007/s11240-014-0641-y.

Teixeira da Silva J.A., Shinoyama H., Aida R., Matsushita Y., RAJ S.K., Chen F.D., 2013. Chrysanthemum biotechnology: Quo vadis? Critical Reviews in Plant Sci. 32(1): 21-52.

Thepsithar C., Thongpukdee A., Daorat A., 2013. Sterilisation of in vitro culture medium of chrysanthemum by plant essential oils without autoclaving. World Academy Sci. Engin. Technol. 80: 722-725.

Tymoszuk A., 2014. Application of silver and copper nanocolloids in disinfection of explants in chrysanthemum in vitro cultures. Nano PL, Symposium A (in press).

Tymoszuk A., Zalewska M., 2012. Application of in vitro cultures of ligulate florets in chrysanthemum breeding. 24 ${ }^{\text {th }}$ International Eucarpia Symposium - Section Ornamentals, Warsaw, Poland, 76.

Tymoszuk A., Zalewska M., 2014a. In vitro adventitious shoot regeneration from ligulate florets in the aspect of application in chrysanthemum breeding. Acta Sci. Pol., Hortorum Cultus 13(2): 45-58.

Tymoszuk A., Zalewska M., 2014b. Biological factors affecting regeneration of adventitious shoots from in vitro isolated ligulate florets of chrysanthemum. Acta Sci. Pol., Hortorum Cultus 13(3): 155-165.

Tymoszuk A., Zalewska M., Lema-Rumińska J., 2014. Regeneration of somatic embryos from in vitro 
isolated ligulate florets of chrysanthemum. Acta Sci. Pol., Hortorum Cultus 13(4): 13-22.

Wang R-R., Gao X-X., Chen L., Huo L-Q., Li M-F., WANG Q-C., 2014. Shoot recovery and genetic integrity of Chrysanthemum morifolium shoot tips following cryopreservation by droplet-vitrification. Sci. Hortic. 176: 330-339.

Yin D.M., Ni D., Song L.L., Zhang Z.G., 2013. Isolation of an alcohol dehydrogenase cDNA from and characterization of its expression in chrysanthemum under waterlogging. Plant Sci. 212: 48-54.

ZalewsKa M., Kulus D., 2013. Cryopreservation of in vitro-grown shoot tips of chrysanthemum by encapsulation-dehydration. Folia Hortic. 25(2): 133140.

ZAlEwSKA M., Kulus D., 2014. Improvement of Chrysanthemum $\times$ grandiflorum /Ramat./Kitam. encapsulation-dehydration cryopreservation protocol. Acta Sci. Pol., Hortorum Cultus 13(2): 97-108.

Zalewska M., Kulus D., Mikula A., 2012. Cryopreservation of chrysanthemum using encapsulation-dehydration. 4th Biennial Photography Competition "Science - the World around Us": 40-41.

Zawadzka M., Trzciński P., Nowak K., Orlikowska T., 2013. The impact of three bacteria isolated from contaminated plant cultures on in vitro multiplication and rooting of microshoots of four ornamental plants. J. Hort. Res. 21(2): 41-51.

Zhou Y., Wang Y.Y., Song Y.R., Gao Z.Y., Liu Y.M., Fan L.J., et al., 2014. Stem apex detoxification culture markedly improved several physiological characters of chrysanthemum 'YUTAI'. Plant Cell Tissue Organ Cult. 119: 369-381.

Zhu W.Y., Zhang F., Chen S.M., Xu L.L., Wang L., WANG H.B., et al., 2014. Intergeneric hybrids between Chrysanthemum morifolium 'Nannongxiaoli' and Artemisia vulgaris 'Variegata' show enhanced resistance against both aphids and Alternaria leaf spot. Euphytica 197(3): 399-408.

Received July 14, 2014; accepted October 22, 2014 